\title{
SCORING MODEL FOR THE DETECTION OF FAKE NEWS
}

\author{
Mihai-Ionuț Pop* \\ Bucharest University of Economic Studies, Romania \\ E-mail:mihai.pop@digitix.ro
}

(Received: November 2019; Accepted: January 2020; Published: March 2020)

\begin{abstract}
Misinformation has always existed and has been promoted by groups of individuals, who share the same interests, in order to reach ideological, political or financial goals. In recent years, the emergence of the Internet and social platforms has opened a new and larger dimension in the dissemination of false content and information. With the help of these new technological means, the process of manipulation has evolved and reached a new level which materialized in the concept of fake news. The negative effects associated with this phenomenon have aroused interest among specialists, who are striving to find efficient instruments in order to combat the dissemination of fake information.

In this context, I have developed a scoring model for the detection of fake news, which aims to combat the spreading of false information regarding specialized economic sectors, such as the energy field. Moreover, the model could also be implemented as an important instrument in the fighting against this negative phenomenon that can affect the way public figures, institutions, companies or industries are being perceived by the public opinion.
\end{abstract}

Keywords: Fake news, social media, scoring model, energy field

\section{JEL Codes: M31}

\section{Introduction}

In recent years, social media platforms have constantly increased their number of active users and have become important tools, whether if we are referring to personal, B2B or B2C communication. The increased impact of social media on society has aroused interest among specialists and researchers, who emphasize both the benefits, as well as the threats associated with these new means of communication. One of the greatest concerns regarding social media is related to its potential for spreading fake news. This issue attracted a lot of attention after the $2016^{\text {th }}$ US presidential election. Although allegations have not yet been proven, it is

*Corresponding author: Mihai-Ionuț Pop.E-mail: mihai.pop@digitix.ro use, distribution, and reproduction in any medium, provided the original author and source are credited.

91 sciendo Studia Universitatis "Vasile Goldis" Arad. Economics Series Vol 30 Issue 1/2020 ISSN: 1584-2339; (online) ISSN: $2285-3065$ 
Pop, M.I., (2020)

Scoring model for the detection of fake news

suspected that the US election process has been influenced through the strategic spreading of fake news on the most popular social media platforms (Timberg, 2016). Moreover, authors point out that in most cases fake news is being spread with the purpose of gaining economic or political benefits (Tantau et al., 2018), thus explaining the high amount of fake content targeting the political sphere and other important economic sectors such as health care, the financial sector or the energy field. Consequently, as a response to public pressure, most social media platforms have implemented measures in order to combat the dissemination of fake news. Still, this negative phenomenon is evolving and affecting social and political events.

In this paper, I propose a scoring model for the identification of fake news, based on the credibility of five elements: the author, the source, the presented data or information, a comparison to other sources and a title check. I believe that the proposed model could successfully be implemented in order to reduce the negative effects of fake news on highly specialized sectors. The described model has been developed in order to filter out fake news related to the energy field, but it could be adapted in order to meet the demands of other important sectors.

\section{Literature review}

For the last couple of years, researchers and academics have started to focus more and more on the effects of social media on individuals and implicitly on our society. Hunt (2015) points out that the power of the internet and of social networks, as an efficient tool for communication and information dissemination, is undeniable. Moreover, the author claims that the internet offers consumers an efficient and fast way of getting informed from multiple sources, an increased content variety, as well as the possibility of collecting information related to products or services and their price (Hunt, 2015). Basically, it offers individuals convenience and alternatives. Nevertheless, social media allows users to create, read and share content and news in communities or groups based on the same interests through platforms such as Twitter, Facebook and YouTube (Hunt, 2015). Unfortunately, besides the opportunities associated with the new means of communication, recent years have emphasized the downside of social media. After the $2016^{\text {th }}$ US Presidential election, the term fake news has begun arousing interest and has been given a new dimension.

Tandoc et al. (2017) point out that two of the most common reasons which lead to the spreading of fake news are related to financial and ideological interests. The real negative impact of fake news on companies, public institutions, consumers or public figures has yet been established, but the fact that the credibility of media outlets has been affected in recent years is well known. Nevertheless, OrellanaRodriguez and Kean (2018) highlight that every form of fake content, which is

92 sciendo Studia Universitatis "Vasile Goldis" Arad. Economics Series Vol 30 Issue 1/2020 ISSN: 1584-2339; (online) ISSN: 2285 - 3065

Web: publicatii.uvvg.ro/index.php/studiaeconomia. Pages $91-102$ 
Pop, M.I., (2020)

Scoring model for the detection of fake news

accessible in the online environment, can progressively undermine the good functioning of the traditional business model of news organizations, by reducing their revenues and implicitly their paying audience.

As already mentioned, the consequences of fake news have not yet been fully analyzed, still, the public concern related to their effects is constantly increasing. A growing concern is that fake news can cause confusion in the fact-checking process and thus undermine the accurate informing of individuals (Jang \& Kim, 2018). Moreover, the authors point out that there is an increasing concern about the negative potential of fake news, which is being spread with the help of social media platforms, in undermining democracy by highlighting the fact that not all society members have the ability to select information and making rational decisions.

Misinformation about political life events is more widespread than before, due to the emerging media environment that simplifies the polarization and fragmentation of partisans (Bakshy et al., 2015). In this regard, Spence et al. (2016) reveal that misinformation can be spread faster and more efficiently through social media platforms when there are a high uncertainty and high demand for certain public information on issues such as crises. Furthermore, Jang and Kim (2018) found out that individuals believe that others are more likely to be manipulated by fake news and therefore, the negative effects associated with this phenomenon rather have an impact on others and less on their own opinions. For example, McKeever et al. note (2019 in press) that passionate Republicans and Democrats believe that members of the other party are more vulnerable to the effects of fake news. This result draws attention to the way party supporters assimilate information. As partisans believe they cannot be influenced by fake news, they may become victims of a false impression that every internally spread information, regardless of its accuracy, is true.

The negative impact of fake news is not only associated with political events, but also with specialized economic or social domains. Waszak et al., (2018) point out that misinformation on topics targeting the medical sector, the general specialized economic and social areas, is not a new phenomenon. On the contrary, its roots are probably as old as medical care itself (Waszak et al., 2018). In their study about the impact of fake news on the healthcare system, the authors have analyzed several medical articles that are available in the virtual environment. They concluded that around $40 \%$ of the most popular links related to medical issues include content classified as being false. Moreover, these links have been distributed over 450,000 times. From the authors' point of view, the most common medical topic associated with fake news refers to vaccines. It appears that articles related to cardiovascular issues are well documented and informative. More than $20 \%$ of the analyzed articles, which include false information, have been generated by a single source 
Pop, M.I., (2020)

Scoring model for the detection of fake news

(Waszak et al., 2018). Furthermore, the authors believe that fake news, targeting highly specialized areas in order to mislead the public opinion, could be identified and marked through constant monitoring and evaluation of the most widespread news on social media platforms.

By encouraging authorities to implement measures designed to signal the domains and websites, which generate fake content, this negative phenomenon could be restrained. Consequently, Jin et al. (2017) highlight that in order to combat fake news, it is essential to identify its origins and dissemination patterns implemented in the online environment. If it would be possible to regulate the dissemination level of fake news promoted by websites and platforms, identified as the main source of false content, then their flow could greatly be attenuated (Jang et al., 2018).

The scientific literature suggests that through education or information regarding this phenomenon, the cognitive ability of individuals in detecting fictional facts could be improved (Allcott \& Gentzkow, 2017; Jang \& Kim, 2018). Another solution is a corrective approach by implementing several verification procedures for online available news. This solution involves providing warnings on certain websites that mark the probability of having fake content or information. Especially in specialized areas, such as the energy sector, it is possible to have such verification procedures (Jang et al., 2018). Moreover, it is useful to detect the origin of fake news and filter information promoted by these sources (Ma et al., 2016). This approach is gaining relevance, given the fact that only a small number of blogs and websites are responsible for constantly spreading fake news.

Our previous research has also shown that consumers easily react to fake news. The results generated by our analysis validated the hypothesis that individuals with a lower educational level will determine a higher spreading degree for posts written in a fake news specific form (Pop \& Ene, 2019; Pelau \& Chinie, 2018).

Moreover, the analysis has indicated that respondents older than 40 years show a higher probability of promoting and sharing posts written in a subjective and challenging manner (Pop et al., 2019, BASIQ). These results correspond to the research conducted by Tantau et al. (2018) which identified a higher engagement among elderly individuals regarding the dissemination of fake news published on social platforms.

The way in which information is perceived has an important role both in the behavior of consumers towards the energy consumption (Pelau \& Acatrinei, 2019; Neagu et al. 2016) and the decisions taken by policymakers.

In this context, the developed model aims to reduce the impact of fake news, by implementing a procedure for the identification of fake news. The model could represent a veracity barometer of fake news that could be used by individuals, who are active in the online environment and strive to fact check the encountered

94 sciendo Studia Universitatis "Vasile Goldis" Arad. Economics Series Vol 30 Issue 1/2020 ISSN: 1584-2339; (online) ISSN: 2285 - 3065

Web: publicatii.uvvg.ro/index.php/studiaeconomia. Pages $91-102$ 
Pop, M.I., (2020)

Scoring model for the detection of fake news

articles. I believe that the model could have a significant role in combating the negative effects of fake news.

\section{Empirical results}

The proposed model aims to reduce the impact of fake news in a very important strategic and economic sector, namely the energy field. It involves the definition of specific criteria, which enable a detailed analysis of the published energy-related news. The model includes the evaluation of the credibility of a lot of information related to the energy field, based on the author who has publishes the news, the source where it has been published, the authenticity of the information based on its credibility and by comparing it to other sources and based on the way its title has been written.

The model relies on the verification of energy-related information. Print and online references related to the energy sector will be daily collected using advanced automated monitoring and reporting tools. This information will be analyzed, verified and categorized either by a team of professionals, including experts with extensive experience in the energy field, as well as investigative journalists specialized and accustomed to the themes and topics related to this economic sector or by several intelligent analysis systems. Following the evaluation process according to the specific criteria, every piece of news will receive a score and will be marked either as neutral or false news. Daily rankings presenting news or articles marked as being fake will be established according to the obtained scores. Nevertheless, the ranking will be divided into two categories, print and online references, and will publicly be available online.

The methodology of the model includes the criteria on which the verification and evaluation of energy-related information are done. The model aims to verify the author, source, title, information and replication of each piece of news that appears in the daily monitoring report. A scoring model is used to evaluate the five mentioned criteria, while the final evaluation is done based on the sum of scores given for each criterion (Pelau, 2009). Each analyzed criterion can obtain a score having values between 0 and 20 points.

The first analysis is done by the authenticity and credibility of the author. If the analyzed article does not have an author or is signed with a false name, the piece of news will receive no points. Depending on the experience of the author, the analyzed reference will receive 20 points if the author is known and has long-term experience and credibility in the field. The information will receive a score of 10 points if the authors are not known by the audience in the field and have not very much experience. The experience and credibility of the authors will be evaluated with the help of the experts involved in the scoring model. The author's check scoring scheme can be observed in figure 1 . 


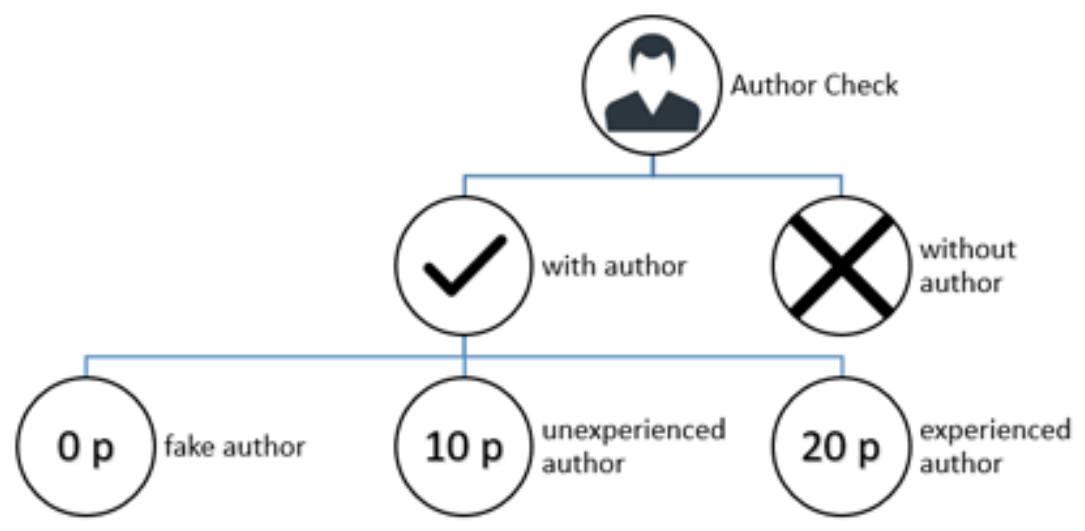

Figure 1 Author Check, the criterion of the model Source: self-research

The second criterion for credibility analysis is the verification of the source. If the article is published by a deceitful website which is recognized as a source of fake news, then it will receive no points. In opposition to this, if the article's source proves to be reliable and it has shown long-time credibility and authenticity of the information, it will receive 20 points. There is also the possibility of a questionable source, which is not marked or recognized as being deceitful. In this case, the article will receive 10 points for its credibility. Important factors in the trustworthiness of the reference include the experience of the editorial team, the prestige of the publication, its history, the number of readers as well as other factors. As seen in figure 2, the following scores are given to news based on the source criterion.

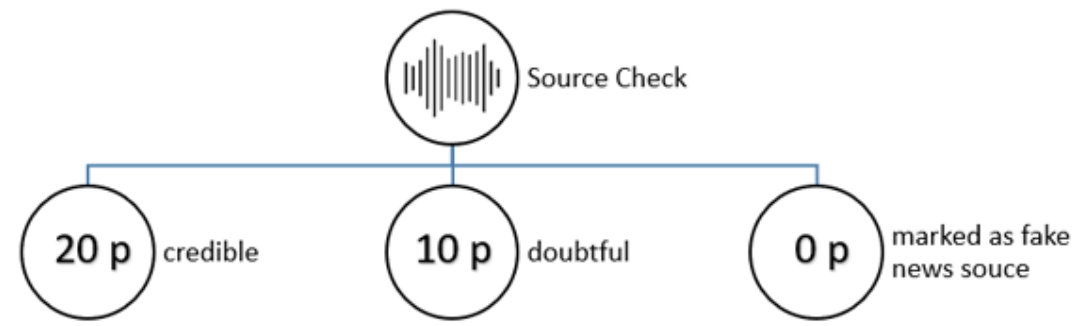

Figure 2 Source Check, the criterion of the model

Source: self-research 
Pop, M.I., (2020)

Scoring model for the detection of fake news

The third criterion refers to the evaluation of the trustworthiness of the information itself. This includes the verification of the information, data and figures included in the article. If these are supported by other official sources, statements and documents, the article will receive 20 points. On the other hand, if the presented data cannot be verified, the reference will only receive 10 points. Moreover, in case the team detects the existence of false information, the article will not receive any points. Figure 3 illustrates the third step of the evaluation process.

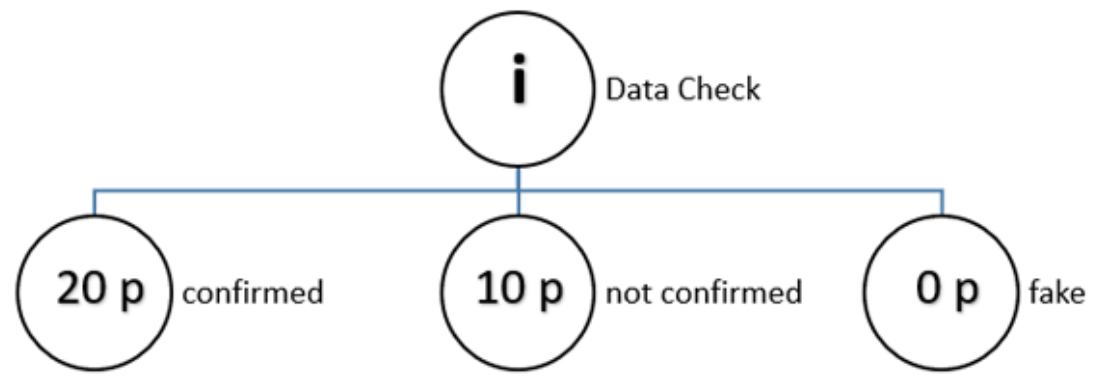

Figure 3 Data Check, the criterion of the model

Source: self-research

The credibility of the presented information will be tested also by comparison with other sources. As it can be observed by analyzing figure 4, the fourth stage of the evaluation process verifies whether the information is confirmed and also published by other sources. For this criterion, the news will receive 20 points if the topic has been picked up by several credible platforms and 0 points if the information is not available at other sources or it is contradicted by other sources.

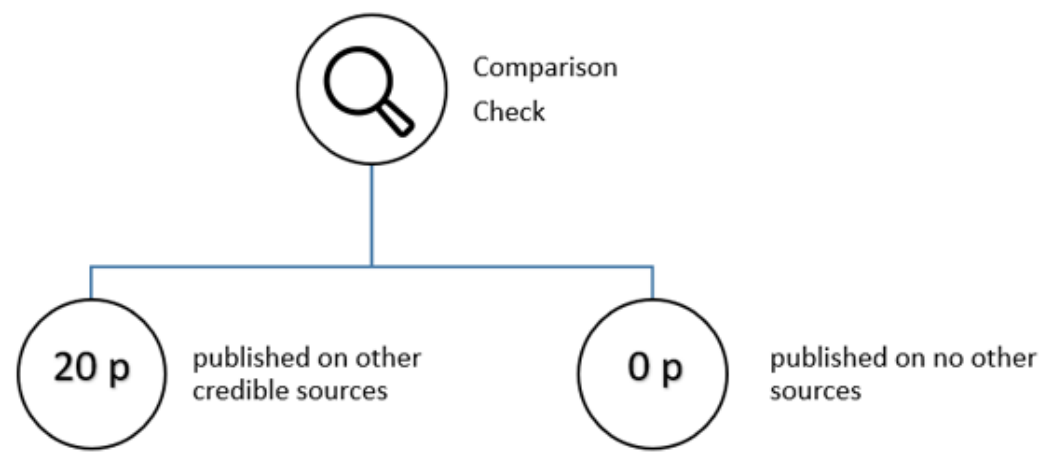

Figure 4 Comparison Check, the criterion of the model

Source: self-research 
Pop, M.I., (2020)

Scoring model for the detection of fake news

The last evaluation criterion for the credibility of news is the way in which the title has been formulated. The title can be another relevant indicator in analyzing the veracity of an article. If the title contains words that have been intentionally used in order to arouse negative emotion or determine a certain action, then the article will not receive any points. On the other hand, if the article has a neutral title, without any click-bait specific words, the news will receive 20 points. Of course, the title of any publication aims to attract the attention of the readers, but any exaggerated formulations, or a contradiction between the breaking news effect of the title and the lack of information in the article, do not have a positive impact on its credibility. Therefore, the match between the formulation of the title and the content of the article is an important factor for its credibility and will receive in the model a score of 20 points. Fake News specific formulations of the title will reduce its credibility. If there is no match between the title and its content, then the article will receive 0 points in the scoring model. If the article contains important information, but the title includes an exaggeration, then the news article will receive 10 points. The title check criterion for the detection of fake news can be observed in figure 5 .

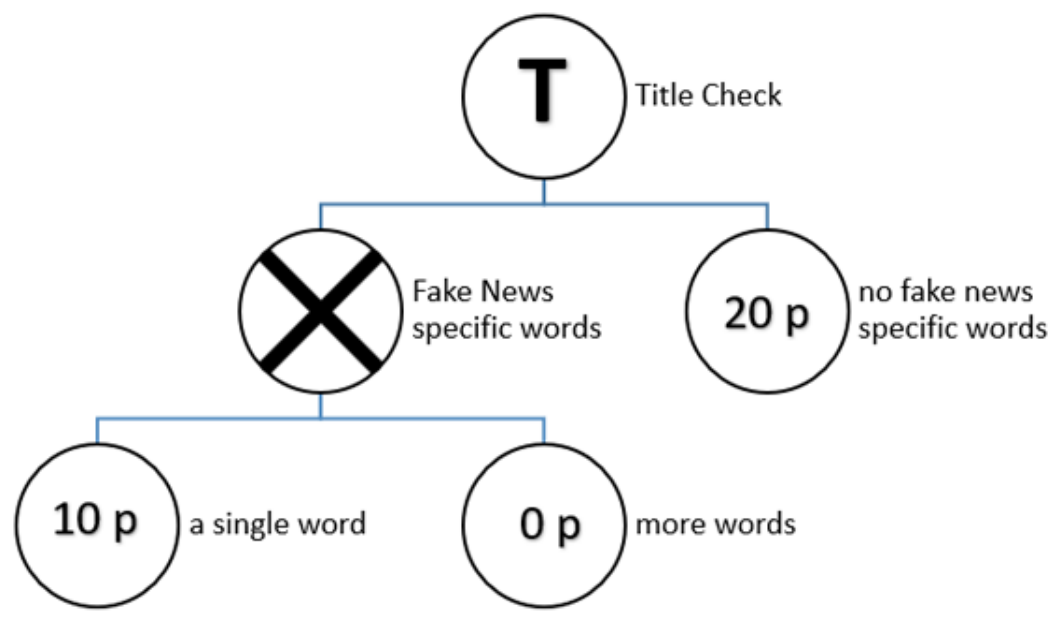

Figure 5 Title Check, the criterion of the model

Source: self-research

Based on the scores given for each of the five mentioned criteria, the total score for each article will be calculated. Articles obtaining more than 60 points will be considered credible, while articles scoring less than 60 points will be defined as fake news. The articles having less than 60 points in the proposed scoring model will be divided into three categories. The articles scoring less than 20 points will

98 sciendo Studia Universitatis "Vasile Goldis" Arad. Economics Series Vol 30 Issue 1/2020 ISSN: 1584-2339; (online) ISSN: $2285-3065$

Web: publicatii.uvvg.ro/index.php/studiaeconomia. Pages $91-102$ 
Pop, M.I., (2020)

Scoring model for the detection of fake news

probably fulfill less than two of the five mentioned criteria and therefore will be considered as being totally fake. Articles scoring between 21 and 40 points fulfill some of the mentioned criteria and will be labeled as mostly fake. A similar situation refers to articles scoring 41-60 points, where some of the credibility criteria are fulfilled and some are not. In this case, the verification should continue. These intervals for the scoring model of the detection of fake news are described in table 1.

Table 1 Intervals for the evaluation of energy-related news

\begin{tabular}{|c|c|}
\hline Interval & Category \\
\hline More than 60 points & Credible information \\
\hline $41-60$ points & Includes some credible information \\
\hline $21-40$ points & Mostly Fake \\
\hline $1-20$ points & Totally Fake \\
\hline
\end{tabular}

Source: self-research

\section{Discussions}

The scoring model for the detection of fake news has the mission of informing the public opinion about the occurrence of fake news, especially to the one related to the energy field. The main objective of the model is to educate the public about the correctness of the existing information as well as to mark and highlight fake news that has been published to affect the integrity of the energy sector and that of its representatives.

In other words, the model aims to create a neutral voice that has the purpose of detecting and unmasking fake news. The identification of fake news is important as it is published and promoted to misinform and for the creation of public pressure, generating direct benefits to certain groups and their economic interest. Nevertheless, the model for the detection of fake news will focus on ensuring the correctness of information for individuals, who are interested in finding genuine and trustworthy print and online available energy-related information and news.

The dissemination of the scoring model for the detection of fake news can be implemented in different ways in the online environment. On one hand, it can be disseminated with the help of fake news related labels associated with the published news articles and on the other hand, it can be presented with the help of a ranking published on a special internet page or with the help of social media networks.

The target groups interested in such an evaluation of fake news are young individuals, who are active in the online environment and are interested in topics related to the energy field. The audience will include individuals, who lack the specific knowledge related to this economic sector and have the role of household 
Pop, M.I., (2020)

Scoring model for the detection of fake news

consumer or, prosumers. Moreover, the published ranking may attract the interest and attention of specialists, who are active in the energy field, have specific training and the ability to understand the complexity of the attacks associated with the spreading of fake news. These individuals will access the model to find out which topics and themes are being targeted and transformed into manipulation tools.

Furthermore, through the constant publishing of the rankings and the main sources of fake news, the model will be interesting for journalists and influencers. The online presence will be reinforced by the development of a Facebook page created with the purpose of daily publishing the fake news rankings to correctly inform users, who are active on the Social Media platforms. Moreover, this communication channel will aim to develop a community of supporters around the project, thus educating and informing the public opinion regarding the energy sector.

\section{Conclusions}

The amount of fake content spread via the Internet and social media platforms, as well as, its negative impact on society have not yet been quantified. Even so, more and more individuals are becoming aware of the phenomenon's existence. As fake news becomes more versatile and complex, it is mandatory to develop efficient instruments and solutions to respond to this challenge and combat its negative effects.

The presented model suggests a mix between automated and human activities, designed as a solution in fighting fake news. Moreover, as already emphasized, in most cases fake news is being spread by real users, rather than fake ones. In this regard, the proposed model also addresses this issue through its educational component. Through the daily reporting of fake news, online active users will become aware of the misleading information they encounter online.

\section{Acknowledgments}

The author thanks the anonymous reviewers and editor for their valuable contribution.

\section{Funding}

This research received no specific grant from any funding agency in the public, commercial, or not - for - profit sectors.

\section{Author Contributions}

The entire article was written by Mihai Ionuț Pop. 
Pop, M.I., (2020)

Scoring model for the detection of fake news

\section{Disclosure Statement}

The authors have not any competing financial, professional, or personal interests from other parties.

\section{References}

1. Allcott, H., Gentzkow, M., (2017), Social media and fake news in the 2016 election, Journal of Economic Perspectives, 2(31), pp. 211-236, https://doi.org/10.1257/ jep.31.2.211

2. Bakshy, E., Messing, S., Adamic, L.A., (2015), Exposure to ideologically diverse news and opinion on Facebook. Science, 348 (6239), pp. 1130-1132, https://doi.org/ $10.1126 /$ science.aaa1160

3. Hunt, K.M., (2015), Gaming the system: Fake online reviews vs. consumer law, Computer law \& security review, 31, pp. 3-25

4. Jang, S.M., Kim, J.K., (2018), Third person effects of fake news: Fake news regulation and media literacy interventions, Computers in Human Behavior, 80 (2018), pp. 295-302

5. Jang, S.M., McKeever, B., McKeever, R., Kim, J.K., (2017), From social media to mainstream news: The information flow of the vaccine-autism controversy in the US, Canada, and the UK, Health Communication, https://doi.org/10.1080/ 10410236 (in press)

6. Jang, S.M., Geng, T., Li, J.Q., Xia, R., Huang, C., Kim, C., Tang, J., (2018), A computational approach for examining the roots and spreading patterns of fake news: Evolution tree analysis, Computers in Human Behavior, 84, pp. 103-113

7. Jin, Z., Cao, J., Guo, H., Zhang, Y., Wang, Y., \& Luo, J., (2017), Detection and analysis of 2016 US presidential election related rumors on Twitter, in International conference on social computing, behavioral-cultural modeling and prediction and behavior representation in modeling and simulation, pp. 14-24

8. Marketingmag.com, (2014), Infographic of the week: Consumer psychology and the ecommerce checkout, Retrieved from http://www.marketingmag.com.au/news/infographicof-the-week-consumer-psychology-and-the-ecommerce-checkout-8029/\#.U0UNto2KDIU

9. Merrill, J.C., (1974), The imperative of freedom: a philosophy of journalistic autonomy: Freedom House

10. Neagu, O., Dumiter, F., Braica, A., (2016), Inequality, economic growth and trade openness: A case study for Central and Eastern European countries (ECE), Amfiteatru Economic Journal, 18 (43), pp. 557-574

11. Orellana-Rodriguez, C., Keane, M.T., (2018), Attention to news and its dissemination on Twitter: A survey, Computer Science Review, 29, pp. 74-94

12. Pelau, C., (2009), Marketing-Controlling - Măsurarea performanţei în marketing, Editura Economică, București

13. Pelau, C., Acatrinei, C., (2019), The Paradox of Energy Consumption Decrease in the Transition Period towards a Digital Society, Energies, 12(8), Article 1428, https://doi.org/10.3390/en12081428.

14. Pelau, C., Chinie A.C., (2018), Econometric Model for Measuring the Impact of the Education Level of the Population on the Recycling Rate in a Circular Economy, Amfiteatru Economic, 20(48), pp. 340-355, http://www.amfiteatrueconomic.ro/ RevistaDetalii_EN.aspx?Cod=1069. 
Pop, M.I., (2020)

Scoring model for the detection of fake news

15. Pop, M.I., Ene, I., (2019), Influence of the educational level on the spreading of Fake News regarding the energy field in the online environment, Proceedings of the $13^{\text {th }}$ International Conference of Business Excellence (ICBE), an article in press

16. Pop, M.I., Pelau, C., Stanescu, M., (2019), Reliability of Social Media Platforms and Online News as Source of Information for Consumers, Proceedings of the $5^{\text {th }}$ International Conference on New Trends in Sustainable Business and Consumption (BASIQ), Bari, Italy, pp. 711-717

17. Tandoc, E.C., Lim, Z.W., Ling, R., (2017), Defining 'fake news', Digit J 2017:1-17, doi: $10.1080 / 21670811.2017 .1360143$

18. Tanțau, A., Pelau, C., Pop, M.I., (2018), Fake news in the energy industry, Proceedings of the 4th BASIQ International Conference on New Trends in Sustainable Business and Consumption (BASIQ), pp. 204-210

19. Timberg, C., (2016), Russian propaganda effort helped spread 'fake news' during the election, experts say, The Washington Post,

Retrieved from: https://www.washingtonpost.com/business/economy/russian-propagandaeffort-helped-spread-fake-news-during-election-experts-say/2016/11/24/793903b6-8a404ca9-b712-716af66098fe_story.html

20. Waszak, P.M., Kasprzycka-Waszak, V., Kubanek, A., (2018), The spread of medical fake news in social media -The pilot quantitative study, Health Policy and Technology 7 , pp. $115-118$ 